\title{
Oxygen Precipitation in Si:O Annealed under High Hydrostatic Pressure
}

\author{
A. Misiuk ${ }^{a}$, J. BĄK-Misiuk ${ }^{b}$, L. Bryja ${ }^{c}$, J. KĄtCKI $^{a}$, \\ J. RATAJCZAK ${ }^{a}$, J. JUN ${ }^{d}$ AND B. SURMA \\ ${ }^{a}$ Institute of Electron Technology, al. Lotników 32/46, 02-668 Warsaw, Poland \\ ${ }^{b}$ Institute of Physics, Polish Academy of Sciences \\ al. Lotników 32/46, 02-668 Warsaw, Poland \\ ${ }^{c}$ Wrocław University of Technology \\ Wyb. Wyspiańskiego 27, 53-370 Wrocław, Poland \\ ${ }^{d}$ High Pressure Research Centre, Polish Academy of Sciences \\ Sokołowska 29/37, 01-142 Warsaw, Poland \\ ${ }^{e}$ Institute of Electronic Materials Technology \\ Wólczyńska 133, 01-919 Warsaw, Poland
}

\begin{abstract}
Effect of hydrostatic pressure up to $1.2 \mathrm{GPa}$ on oxygen-implanted silicon, Si:O $\left(\mathrm{O}^{+}\right.$dose, $D$, within the $6 \times 10^{17}-2 \times 10^{18} \mathrm{~cm}^{-2}$ range $)$, treated at 1230-1570 K, was investigated by X-ray, transmission electron microscopy and photoluminescence methods. The pressure treatment affects oxygen precipitation and defect creation, especially in low oxygen dose implanted Si:O $\left(D=6 \times 10^{17} \mathrm{~cm}^{-2}\right)$. Such investigation helps in understanding the stress related phenomena in $\mathrm{Si}$ wafers with buried insulating layer.
\end{abstract}

PACS numbers: 61.10.-i, 61.72.Yx, 81.40.Vw

\section{Introduction}

Separation by oxygen implantation (SIMOX) is a widely known technology for producing silicon-on-insulator (SOI) structures. This technology consists of two steps:

(a) implantation of oxygen ions into single crystalline Si substrate, to prepare $\mathrm{Si}: \mathrm{O}$, and

(b) high temperature (HT) treatment of Si:O, usually at $\geq 1570 \mathrm{~K}$. 
Initially randomly distributed oxygen atoms precipitate during annealing and create dispersed sub-stoichiometric $\mathrm{SiO}_{2-x}$ clusters and agglomerates, and eventually, for high $\left(\geq 1 \times 10^{18} \mathrm{~cm}^{-2}\right)$ implanted oxygen doses, $D$, the insulating buried layer composed of stoichiometric $\mathrm{SiO}_{2}$. This effect is critically dependent on $D$ and conditions of implantation and the subsequent treatment.

Creation of $\mathrm{SiO}_{2-x}$ clusters and precipitates in $\mathrm{Si}: \mathrm{O}$ is concomitant with stress, both at the implantation stage and during the treatment, because the volume of $\mathrm{SiO}_{2}$ is about twice that of $\mathrm{Si}$ and thermal expansion of $\mathrm{Si}$ is much higher than that of $\mathrm{SiO}_{2}$.

It was expected that, by controlled change of strain resulting from enhanced hydrostatic pressure (HP) of ambient gas at annealing of $\mathrm{Si}: \mathrm{O}$, it would be possible to obtain information on effect of strain on the structure of $\mathrm{Si}: \mathrm{O}$ and of the $\mathrm{Si} / \mathrm{SiO}_{2}$ boundary (that last one for the SOI-like structures prepared from Si:O with $D \geq$ $\left.1 \times 10^{18} \mathrm{~cm}^{-2}\right)$.

Valuable data concerning oxygen precipitation have been reported for Czochralski silicon $(\mathrm{Cz}-\mathrm{Si})$ treated under enhanced hydrostatic pressure of inert gas (HT-HP treatment) [1, 2]. The HT-HP treatment has been proven to exert pronounced effect on defect creation in Si:O [3] and in SOI structures prepared by direct bonding technology [4].

Effect of the HT-HP treatment on oxygen precipitation and structure of oxygen-implanted $\mathrm{Cz}$-Si and floating zone $(\mathrm{Fz})$ grown Si single crystals with $D \geq$ $6 \times 10^{17} \mathrm{~cm}^{-2}$ was investigated in this work. Some results for the Si:O samples prepared by low-dose implantation $\left(D \leq 1 \times 10^{17} \mathrm{~cm}^{-2}\right)[3,5]$ were also presented for reference.

\section{Experimental}

The 001 and 111 oriented $\mathrm{Cz}$-Si and $\mathrm{Fz}$-Si wafers were implanted at $650 \mathrm{~K}$ by $\mathrm{O}^{+}$ions $\left(D=(6-20) \times 10^{17} \mathrm{~cm}^{-2}\right.$, energy $50-170 \mathrm{keV}$, oxygen projected range $\left.R_{\mathrm{p}}=0.12-0.37 \mu \mathrm{m}\right)$. Characteristic features of investigated $\mathrm{Si}: \mathrm{O}$ samples are presented in Table.

\section{TABLE}

Characteristics of typical investigated samples.

\begin{tabular}{c|c|c|c}
\hline \hline Method of growth & $\begin{array}{c}\text { Crystallographic } \\
\text { orientation }\end{array}$ & $D\left[\mathrm{~cm}^{-2}\right]$ & $E[\mathrm{keV}]$ \\
\hline $\mathrm{Fz}$ & 001 & $6 \times 10^{17}$ & 170 \\
$\mathrm{Fz}$ & 111 & $1.1 \times 10^{18}$ & 50 \\
$\mathrm{Cz}$ & 001 & $2 \times 10^{18}$ & 50
\end{tabular}

The samples of about $12 \times 8 \times 0.6 \mathrm{~mm}^{3}$ dimension were cut from the $\mathrm{Si}: \mathrm{O}$ wafers and annealed under $10^{5} \mathrm{~Pa}$ (atmospheric pressure) or HT-HP treated at up 
to $1570 \mathrm{~K}$ under argon pressure up to $1.2 \mathrm{GPa}$, typically for $5 \mathrm{~h}$. The equipment used for that treatment was described elsewhere [2]. The samples were investigated by X-ray reciprocal space mapping (XRRSM, $\mathrm{Cu} K_{\alpha}$ radiation). In what follows, the axes on the XRRSM figures are marked in $\lambda / 2 d$ units $(\lambda-\mathrm{X}$-ray wavelength, $d$ - interplanar distance).

White beam synchrotron topography (done at ESRF, ID19 beam line), cross-sectional transmission electron microscopy (TEM) and photoluminescence (PL) measurements (that latter one at $10 \mathrm{~K}$, with excitation by the $488 \mathrm{~nm}$ line of argon laser) were also done for some samples.

\section{Results and discussion}

It has been reported earlier [3] that the HT-HP treatment at $\geq 1230 \mathrm{~K}$ of the Si:O samples implanted with low oxygen doses $\left(D \leq 1 \times 10^{17} \mathrm{~cm}^{-2}\right)$ resulted in creation of dispersed $\mathrm{SiO}_{2-x}$ clusters/precipitates. Almost no dislocations were formed at (1230-1400) $\mathrm{K}-(0.6-1.2) \mathrm{GPa}$ for the samples implanted with $D \leq$ $1 \times 10^{16} \mathrm{~cm}^{-2}$, contrary to the case of Si:O annealed under $10^{5} \mathrm{~Pa}[3]$. This effect can be related to HP-induced decrease in the misfit, $\varepsilon$, at the $\mathrm{SiO}_{2-x}$ precipitate/Si boundary [3,6], in accordance with Eq. (1)

$$
\varepsilon=\varepsilon_{0}+\frac{K_{\mathrm{SiO}_{2-x}}\left[\Delta T\left(\beta_{\mathrm{SiO}_{2-x}}-\beta_{\mathrm{Si}}\right)+\mathrm{HP}\left(1 / K_{\mathrm{Si}}-1 / K_{\mathrm{SiO}_{2-x}}\right)\right]}{3 K_{\mathrm{SiO}_{2-x}}+4 G_{\mathrm{Si}}},
$$

where $\varepsilon_{0}$ - initial misfit at the $\mathrm{SiO}_{2}$ precipitate/Si matrix boundary at $295 \mathrm{~K}$, $10^{5} \mathrm{~Pa} ; \beta_{\mathrm{SiO}_{2-x}}$ and $\beta_{\mathrm{Si}}$ - coefficients of volume thermal expansion, $K_{\mathrm{SiO}_{2-x}}$ and $K_{\mathrm{Si}}$ - bulk moduli and $G_{\mathrm{Si}}$ - shear modulus (the bottom indices denote the respective material)

The shear stress at the $\mathrm{SiO}_{2-x}$ precipitate/Si matrix boundary decreases with $\mathrm{HP}$, because $K_{\mathrm{Si}}>K_{\mathrm{SiO}_{2-x}}$ (for stoichiometric materials at $298 \mathrm{~K}: K_{\mathrm{Si}}=$ $9.8 \times 10^{10} \mathrm{~Pa}$ and $\left.K_{\mathrm{SiO}_{2}}=4 \times 10^{10} \mathrm{~Pa}[7]\right)$. It means that less dislocations will be created at HP, moreover, that oxygen precipitates of decreased dimension are formed at HT-HP $[2,3]$.

The HT-HP treatment of Si:O implanted with $D=6 \times 10^{17} \mathrm{~cm}^{-2}$ resulted in creation of a buried quasi-continuous $\mathrm{SiO}_{2}$ layer (Fig. 1A), while for Si:O with $D \geq 1 \times 10^{18} \mathrm{~cm}^{-2}$ a continuous $\mathrm{SiO}_{2}$ layer was formed (Fig. 1B-D). Depending on $D$ and on conditions of the treatment, presence of dislocations at the $\mathrm{SiO}_{2}$ layer/matrix boundary was detected (Fig. 1B, D).

Oxygen precipitates and other defects were recognized by $\mathrm{X}$-ray synchrotron topography only in the $\mathrm{Si}: \mathrm{O}$ samples implanted with low oxygen doses, $D \leq$ $1 \times 10^{14} \mathrm{~cm}^{-2}$; the images of individual defects (precipitates) were overlapping for the HT-HP treated $\mathrm{Si}: \mathrm{O}$ samples prepared with use of higher $\mathrm{O}^{+}$doses.

Two-dimensional XRRSM's were recorded near the 004 and 333 reciprocal space points for the annealed and HT-HP treated Si:O samples. 


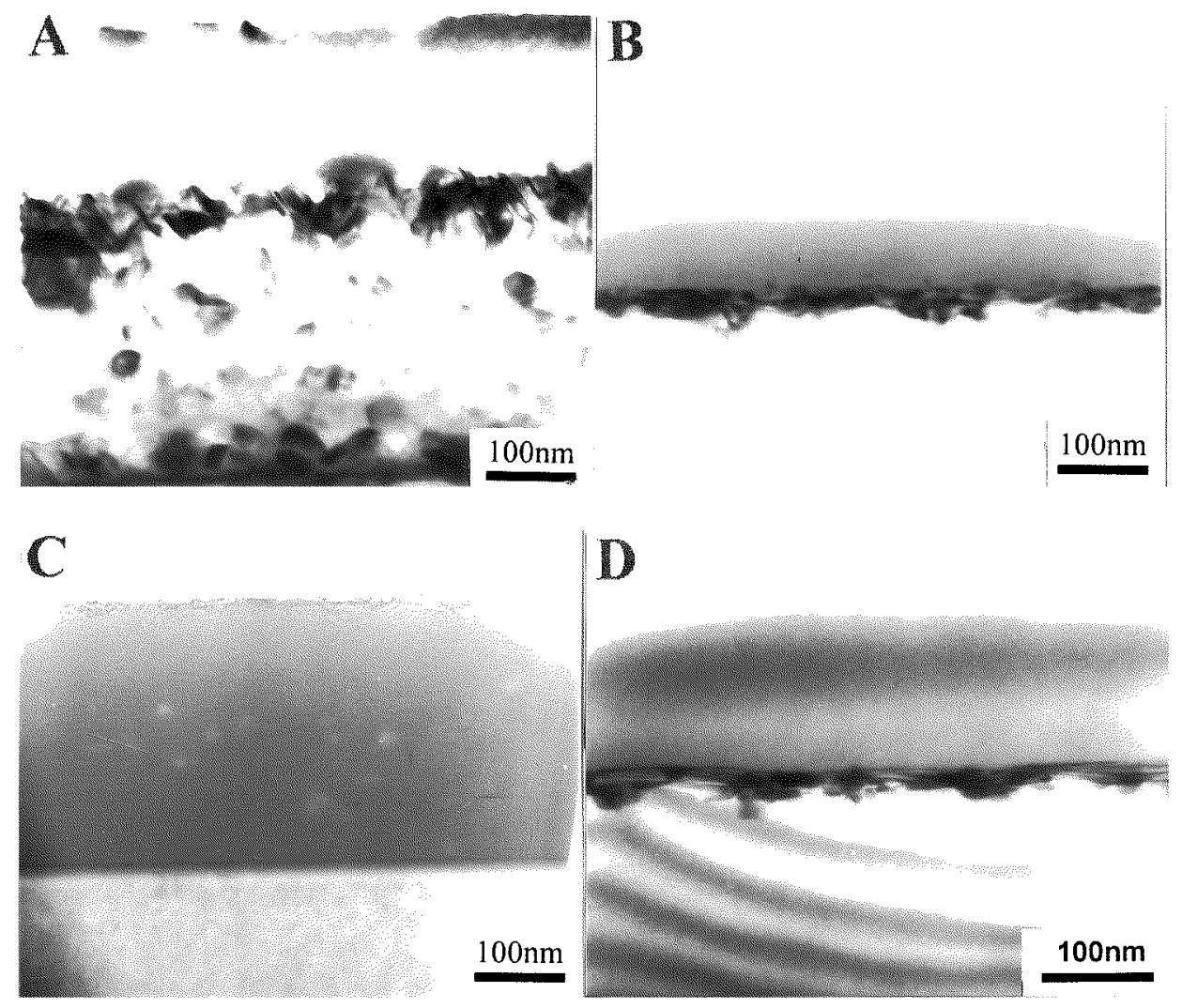

Fig. 1. TEM images of Si:O samples HT-HP treated for 5 h. (A) 001 oriented Fz-Si:O $\left(D=6 \times 10^{17} \mathrm{~cm}^{-2}, 170 \mathrm{keV}, R_{\mathrm{p}}=0.37 \mu \mathrm{m}\right)$ treated at $1400 \mathrm{~K}-1.0 \mathrm{GPa} ;$ (B) 111 oriented Fz-Si:O $\left(D=1.1 \times 10^{18} \mathrm{~cm}^{-2}, 50 \mathrm{keV}, R_{\mathrm{p}}=0.12 \mu \mathrm{m}\right)$ treated at $1400 \mathrm{~K}-$ $1.14 \mathrm{GPa}$; (C) as (B) but treated at $1570 \mathrm{~K}-10^{7} \mathrm{~Pa}$; (D) 001 oriented Cz-Si:O ( $D=$ $\left.2 \times 10^{18} \mathrm{~cm}^{-2}, 50 \mathrm{keV}, R_{\mathrm{p}}=0.12 \mu \mathrm{m}\right)$ treated at $1400 \mathrm{~K}-1.2 \mathrm{GPa}$.

The treatment at $1230 \mathrm{~K}-1 \mathrm{GPa}$ of the 001 oriented $\mathrm{Fz}-\mathrm{Si}: \mathrm{O}$ samples $(D=$ $6 \times 10^{17} \mathrm{~cm}^{-2}$ ) results in negligible diffuse scattering which, however, increases strongly with temperature and pressure, being especially pronounced for the sample treated at $1570 \mathrm{~K}-1.2 \mathrm{GPa}$ (Fig. 2). The oxygen dose equal to $6 \times 10^{17} \mathrm{~cm}^{-2}$ is not sufficient for creating fully stoichiometric $\mathrm{SiO}_{2}$ buried layer at annealing/treatment (Fig. 1A), so enhanced diffuse scattering from such samples can be considered as an evidence of numerous but small silicon clusters present within the buried oxide layer.

PL spectra of Si:O samples treated at $1570 \mathrm{~K}$ are presented in Fig. 3. The treatment of the reference [8] low-dose oxygen-implanted samples at $1570 \mathrm{~K}$ results in a presence of wide dislocation-related PL lines near $0.81 \mathrm{eV}$ (their intensity decreases with HP, compare spectra $A$ and $B$ ). The samples with $D=6 \times 10^{17} \mathrm{~cm}^{-2}$ 


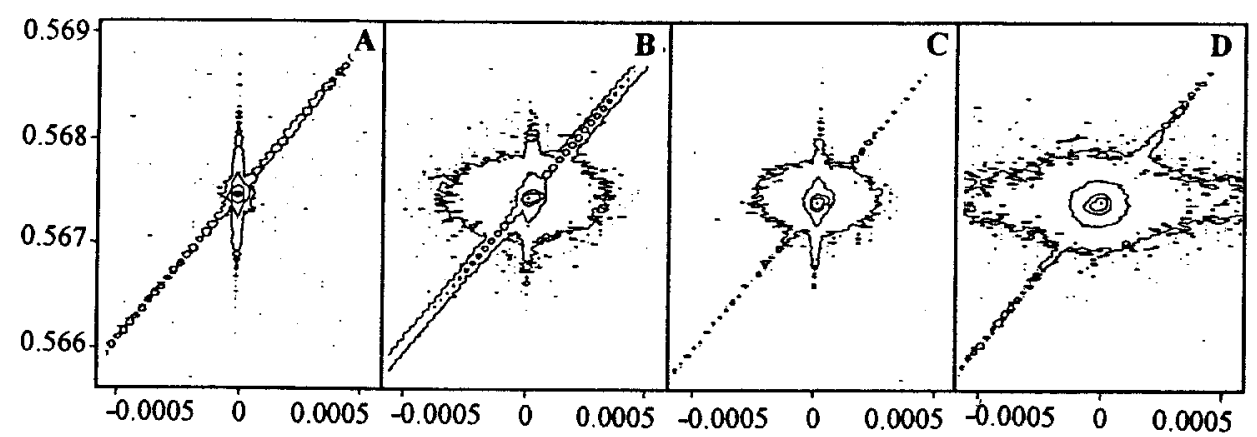

Fig. 2. Two-dimensional XRRSM's recorded near 004 reciprocal space point for 001 oriented Fz-Si:O samples $\left(D=6 \times 10^{17} \mathrm{~cm}^{-2}, 170 \mathrm{keV}, R_{\mathrm{p}}=0.37 \mu \mathrm{m}\right)$ treated for $5 \mathrm{~h}$ at: (A) $1230 \mathrm{~K}-1 \mathrm{GPa}$; (B) $1400 \mathrm{~K}-1.2 \mathrm{GPa}$; (C) $1570 \mathrm{~K}-10^{7} \mathrm{~Pa}$; (D) $1570 \mathrm{~K}-1.2 \mathrm{GPa}$. The axes are marked in $\lambda / 2 d$ units.

(with the quasi-continuous buried $\mathrm{SiO}_{2}$ layer [9]) indicate strong $\mathrm{PL}$ at about $1.02 \mathrm{eV}$, similar to that detected in annealed hydrogen- and helium-implanted silicon, presumably related to some point defects [10]. The PL peak at $1.1 \mathrm{eV}$ corresponds to band-to-band transition; its intensity is higher for the samples of higher structural perfection.

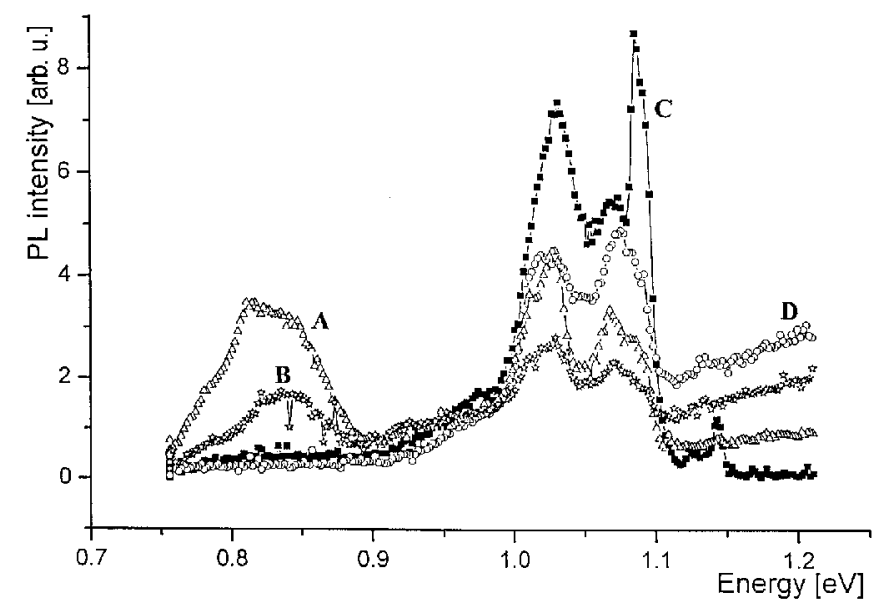

Fig. 3. PL spectra of Si:O samples ( $A$ and $B-D=1 \times 10^{17} \mathrm{~cm}^{-2}, 200 \mathrm{keV}, R_{\mathrm{p}}=$ $0.4 \mu \mathrm{m} ; C$ and $\left.D-D=6 \times 10^{17} \mathrm{~cm}^{-2}, 170 \mathrm{keV}, R_{\mathrm{p}}=0.37 \mu \mathrm{m}\right)$ treated for $5 \mathrm{~h}$ at: $A$ and $C-1570 \mathrm{~K}-10^{7} \mathrm{~Pa} ; B$ and $D-1570 \mathrm{~K}-1.2 \mathrm{GPa}$.

The HT-HP treatment of Si:O samples implanted with the $\mathrm{O}^{+}$flux of high dose but low energy ( $\left.D=1.1 \times 10^{18} \mathrm{~cm}^{-2}, 50 \mathrm{keV}\right)$ leads to X-ray diffuse scattering almost independent of the treatment conditions (Fig. 4). In that case the HT-HP treatment affects creation of defects at the $\mathrm{SiO}_{2} / \mathrm{Si}$ boundary, but not that inside 
of the oxide layer, the latter being rather uniform and reaching sample surface (Fig. 1B-D). The $\mathrm{SiO}_{2} / \mathrm{Si}$ interface in such samples is strongly dislocated because of misfit existing in this area. Point defects located at the interface form small precipitates gettered at the dislocations.

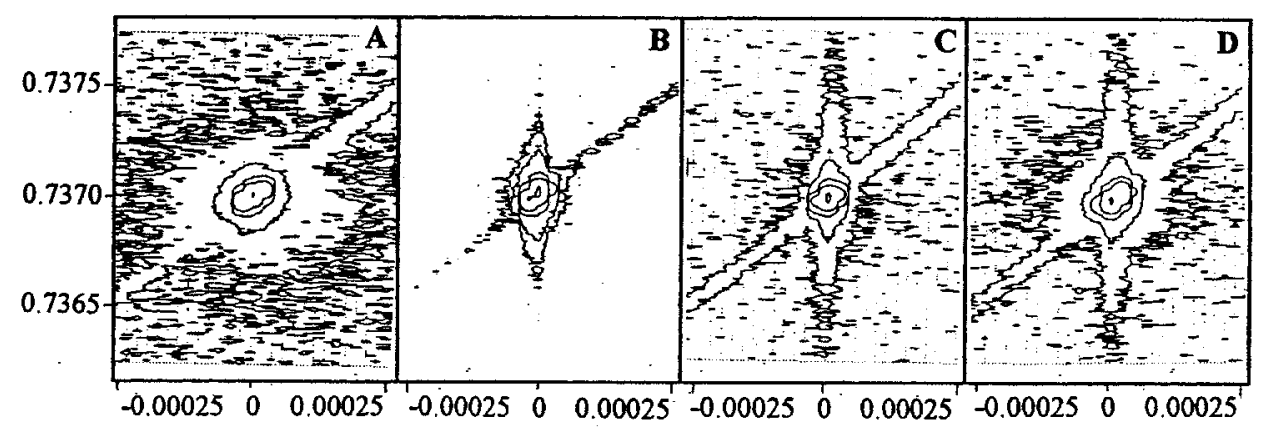

Fig. 4. Two-dimensional XRRSM's recorded near 333 reciprocal space point for 111 oriented Fz-Si:O samples $\left(D=1.1 \times 10^{18} \mathrm{~cm}^{-2}, 50 \mathrm{keV}, R_{\mathrm{p}}=0.12 \mu \mathrm{m}\right)$ treated for $5 \mathrm{~h}$ at: (A) $1230 \mathrm{~K}-1.2 \mathrm{GPa}$; (B) $1400 \mathrm{~K}-1.14 \mathrm{GPa}$; (C) $1570 \mathrm{~K}-10^{7} \mathrm{~Pa}$; (D) $1570 \mathrm{~K}-1.2 \mathrm{GPa}$. The axes are marked in $\lambda / 2 d$ units.

PL spectra of Si:O samples with $D=1.1 \times 10^{18} \mathrm{~cm}^{-2}$, treated at $1400 \mathrm{~K}$, are presented in Fig. 5. Enhanced HP during the treatment results in quenching of the dislocation-related PL line at $0.81 \mathrm{eV}$. The treatment of these samples at $1570 \mathrm{~K}$ leads to disappearance of that dislocation-related PL peak.

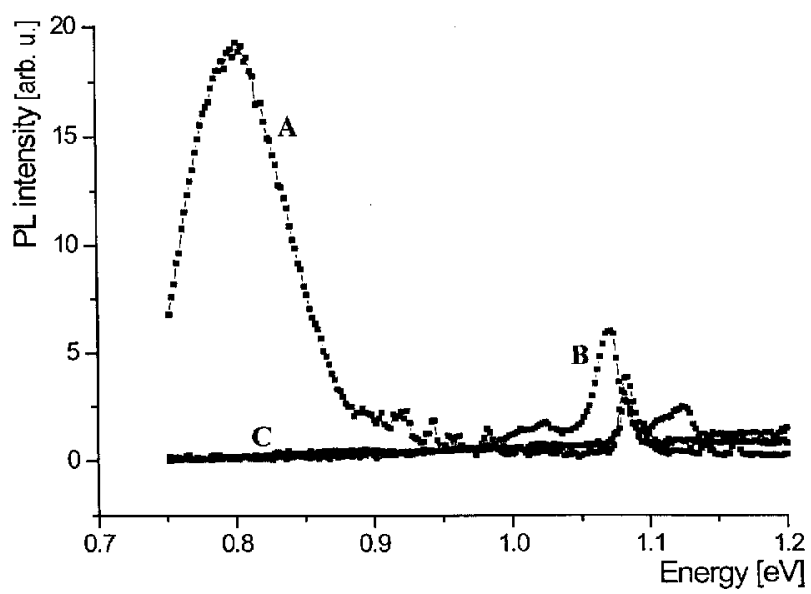

Fig. 5. PL spectra of Fz-Si:O samples $\left(D=1.1 \times 10^{18} \mathrm{~cm}^{-2}, 50 \mathrm{keV}, R_{\mathrm{p}}=0.12 \mu \mathrm{m}\right)$ annealed/treated at $1400 \mathrm{~K}$ for $5 \mathrm{~h} . A$ - at $10^{5} \mathrm{~Pa} ; B$ - at $0.6 \mathrm{GPa} ; C$ - at $1.14 \mathrm{GPa}$. 


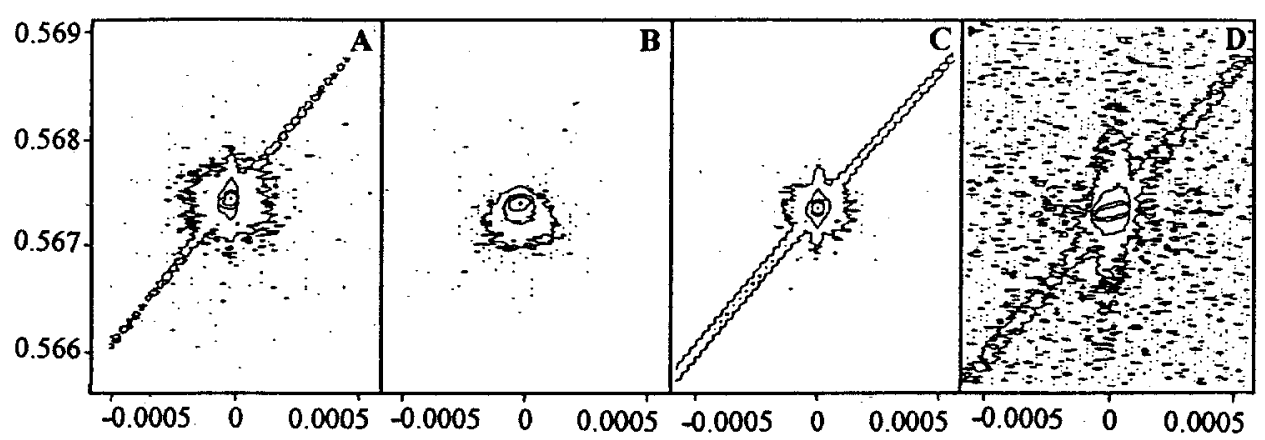

Fig. 6. Two-dimensional XRRSM's recorded near 004 reciprocal space point for 001 oriented Cz-Si:O samples ( $\left.D=2 \times 10^{18} \mathrm{~cm}^{-2}, 50 \mathrm{keV}, R_{\mathrm{p}}=0.12 \mu \mathrm{m}\right)$ annealed/treated for $5 \mathrm{~h}$ at: (A) $1230 \mathrm{~K}-10^{5} \mathrm{~Pa}$; (B) $1230 \mathrm{~K}-1.2 \mathrm{GPa}$; (C) $1400 \mathrm{~K}-10^{5} \mathrm{~Pa}$; (D) $1400 \mathrm{~K}-1.14 \mathrm{GPa}$. The axes are marked in $\lambda / 2 d$ units.

The HT-HP treatment of Si:O implanted with $D=2 \times 10^{18} \mathrm{~cm}^{-2}$ results in X-ray diffuse scattering of low intensity (Fig. 6). This is an evidence that the $\mathrm{HT}-\mathrm{HP}$ treatment affects, with respect to defect creation, mostly the $\mathrm{SiO}_{2}$ layer/Si boundary (compare Fig. 1B, D). The wide but weak PL peak at $0.8 \mathrm{eV}$ detected after the treatment at $1400 \mathrm{~K}-(0.6-1.2) \mathrm{GPa}$ can be related to presence of contamination in the surface-reaching $\mathrm{SiO}_{2}$ layer [11]. The treatment at $1400 \mathrm{~K}-\mathrm{HP}$ of the samples with $D \geq 1 \times 10^{17} \mathrm{~cm}^{-2}$ did not suppress fully the creation of dislocations (Fig. 1B-D, Fig. 3). In the case of samples treated at HT $\geq 1400 \mathrm{~K}$ and $\mathrm{HP}=1.2 \mathrm{GPa}$, the quasi-continuous $\mathrm{SiO}_{2-x}$ layer (containing the crystalline Si inclusions) grew in the samples implanted with $D=6 \times 10^{17} \mathrm{~cm}^{-2}$ while, in the case of higher oxygen doses, that layer seems to be continuous and stoichiometric. Tensile stress in the near-surface Si layer, exerted by not fully stoichiometric $\mathrm{SiO}_{2-x}$ of higher volume than that of $\mathrm{Si}$, was responsible for formation of dislocations. They were detected in $\mathrm{Si}$ at the bottom and at the top $\mathrm{SiO}_{2-x} / \mathrm{Si}$ interfaces of the buried layer in the case of Si implanted with $D=6 \times 10^{17} \mathrm{~cm}^{-2}$.

The treatment of Si:O sample with $D=(1.1-2) \times 10^{18} \mathrm{~cm}^{-2}$ at $1400 /$ $1570 \mathrm{~K}-10^{7} \mathrm{~Pa} / 1.2 \mathrm{GPa}$ for $5 \mathrm{~h}$ resulted in creation of continuous buried $\mathrm{SiO}_{2}$ layer. Only limited number of dislocations were detected for the samples treated at about $1400 \mathrm{~K}$ (Fig. 1B, D). Dislocations were practically absent in Si:O treated at $1570 \mathrm{~K}$ (Fig. 1C), while some point-like defects were detected in these samples by XRRSM and PL measurements (Fig. 4-6). The as-implanted Si:O samples consist of the bulk of perfect crystallinity, of thin near-surface layer containing most implanted oxygen atoms and of the top Si layer (very thin or even not existing for the case of low energy implantation - Fig. 1B-D). The implantation-induced damages (also present at the bottom $\mathrm{SiO}_{2} / \mathrm{Si}$ boundary) were dependent on oxygen dose, energy, Si substrate temperature during implantation, etc.

An increase in $D$ is related to an increase in energy "introduced" by oxygen atoms into the Si lattice and so in more pronounced structural disturbances. 
Two different groups of the HT-HP treated Si:O samples were investigated: with $D=6 \times 10^{17} \mathrm{~cm}^{-2}$ and with $D=(1.1-2) \times 10^{18} \mathrm{~cm}^{-2}$. While at HT-HP the individual silicon clusters were created in the $\mathrm{SiO}_{2-x}$ continuous-like layer present in Si:O samples belonging to the first group, the continuous $\mathrm{SiO}_{2}$ layer was found to be created in the samples implanted with $D=(1.1-2) \times 10^{18} \mathrm{~cm}^{-2}$.

The following HT-HP induced effects seem to be most responsible for the reported observations:

- oxygen-containing layer is highly disturbed just ater implantation. At annealing/HT-HP treatment the oxygen containing agglomerates, at first of the sub-stoichiometric $\mathrm{SiO}_{2-x}$ composition, are created mostly within the area disturbed by oxygen implantation;

- strain/misfit at the $\mathrm{SiO}_{2-x} / \mathrm{Si}$ boundary decreases and even can change its sign with $\mathrm{HP}$ (Eq. (1)). More but smaller $\mathrm{SiO}_{2-x}$ agglomerates are created in treated $\mathrm{Si}: \mathrm{O}$ at the first stages of treatment. Such HT-HP treated samples indicate presence of silicon particles inside of the oxide layer while creation of other extended defects is strongly suppressed. The continuous $\mathrm{SiO}_{2}$ layer is created in the $\mathrm{Si}$ :O samples for $D>6 \times 10^{17} \mathrm{~cm}^{-2}$, especially at the highest temperaturespressures $(1570 \mathrm{~K}$ and $\mathrm{HP} \geq 0.01 \mathrm{GPa})$. The structural perfection of Si:O layers seems to be improved with increased HT and HP.

\section{Conclusions}

The temperature-pressure treatment results in specific, treatment related change of the Si:O structure, especially as it concerns the defects (dislocation) density.

In the case of $\mathrm{Si}: \mathrm{O}$ implanted with oxygen dose equal to $6 \times 10^{17} \mathrm{~cm}^{-2}$, the quasi-continuous buried $\mathrm{SiO}_{2-x}$ layer, containing silicon inclusions, is created at $\geq 1400 \mathrm{~K}$. The features of that layer are dependent on treatment conditions; the HP-induced changes occur both inside the layer and at the layer/Si substrate interface.

In the case of $\mathrm{Si}: \mathrm{O}$ implanted with higher oxygen doses $(D=$ $\left.(1.1-2) \times 10^{18} \mathrm{~cm}^{-2}\right)$, the continuous $\mathrm{SiO}_{2}$ layer was created; that layer reached the Si surface. The HP-induced changes took place mostly at the layer/substrate interface.

Detailed investigation of the HT-HP treatment effect on the oxygen-implanted Si:O structures offers also a unique opportunity to study interaction, at high temperatures-pressures, of reactive components (such as oxygen) with the near-surface substrate atoms in conditions of controlled stress. Such investigations are of interest for understanding effects during fabrication and processing the SIMOX structures. 


\section{Acknowledgments}

This work was partially supported by the grant no. 8T11B 07219 of the State Committee for Scientific Research. The help of Dr. J. Härtwig from the ESRF Grenoble, Dr. I.V. Antonova from the Institute of Semiconductor Physics, RAS, Novosibirsk and of Mr. T. Koska and M. Prujszczyk from the Institute of Electron Technology, Warsaw during sample preparation, treatment and measurements is gratefully acknowledged.

\section{References}

[1] A. Misiuk, J. Härtwig, E. Prieur, M. Ohler, J. Bąk-Misiuk, J. Domagała, B. Surma, Acta Phys. Pol. A 91, 987 (1997).

[2] A. Misiuk, Mater. Phys. Mech. 1, 119 (2000).

[3] A. Misiuk, A. Barcz, J. Ratajczak, M. Lopez, A. Romano-Rodriguez, J. Bąk-Misiuk, H.B. Surma, J. Jun, I.V. Antonova, V.P. Popov, Mater. Sci. Engineer. B 73, 134 (2000).

[4] J. Bąk-Misiuk, J. Domagała, A. Misiuk, J. Sadowski, Z.R. Zytkiewicz, J. Trela, I.V. Antonova, Thin Solid Films 380, 117 (2000).

[5] A. Misiuk, H.B. Surma, I.V. Antonova, V.P. Popov, J. Bąk-Misiuk, M. Lopez, A. Romano-Rodriguez, A. Barcz, J. Jun, Solid State Phenom. 69-79, 345 (1999).

[6] A. Misiuk, A. Barcz, J. Ratajczak, I.V. Antonova, J. Jun, Solid State Phenom. 82-84, 115 (2002).

[7] J. Jung, Philos. Mag. A 50, 257 (1984).

[8] A. Misiuk, A. Barcz, J. Ratajczak, J. Kątcki, J. Bąk-Misiuk, L. Bryja, B. Surma, G. Gawlik, Cryst. Res. Technol. 36, 933 (2001).

[9] J. Jiao, B. Johnson, S. Seraphin, M.J. Anc, R.P. Dolan, B.F. Cordts, Mater. Sci. Engineer. B 72, 150 (2000).

[10] A.G. Ulyashin, R. Job, W.R. Fahrner, A.V. Mudryi, A.I. Patuk, A. Shakin, Mater. Sci. Semicond. Process. 4, 297 (2000).

[11] Ying Xue Li, Xing Zhang, Yan Luo, Yang Yuan Wang, J. Non-Cryst. Solids 254, 134 (1999). 